\title{
Characterization of Carbon Nanotube Reinforced Aluminium Nano- composite using Field Emission Scanning Electron Microscope
}

\author{
Umma Abdullahi, Md Abdul Maleque and Mohammad Yeakub Ali
}

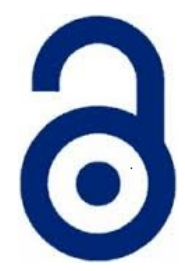

Received: 21 March 2018

Accepted: 27 March 2018

Published: 30 March 2018

Publisher: Deer Hill Publications

Creative Commons: CC BY 4.0

\begin{abstract}
Carbon nanotubes (CNT) is a promising fibrous materials for development of nanocomposite especially aluminium (AI) matrix nanocomposites as CNT exhibited extraordinary mechanical properties and high aspect ratios. The dispersion is the main factor for a quality CNT-Al nanocomposite that affects the uniformity in mixture leading to the enhanced mechanical and wear behaviour. The present study emphasizes on the characterization of carbon nanotube dispersion by means of field emission scanning electron microscope after synthetization of new nanocomposite. The mixing of the reinforcement and matrix powders was performed in ball mill for 2 hours at 250 $\mathrm{rpm}$. The result shows the homogeneous distribution of CNT in Al-matrix. The morphological characterization under FESEM provides insight features of CNT-AI nano-composite with the ball milling parameter on the sintering.
\end{abstract}

Keywords: Carbon nanotube; Aluminium powder; Dispersion; Characterisation; FESEM

\section{INTRODUCTION}

Aluminium (Al) matrix composite can be used for many applications including aviation, aircraft and automotive industries due to the lower density as many components require weight reduction for less fuel consumption which in turn can save the environment. Advancement of the research in the carbon nanotube was embarked after finding of carbon nanotubes (CNTs) by rolling a graphene sheets [1]. A multiwalled carbon nanotube (MWCNT) is consisting of multiple rolled layers or concentric tubes of carbon or graphite material. Past research revealed that MWCNTs have extraordinary properties compared to carbon fibres, such as rigidity is approximately $1000 \mathrm{GPa}$ and thermal conductivity of up to $6000 \mathrm{~W} \mathrm{mK} \mathrm{[2].} \mathrm{Different} \mathrm{processing} \mathrm{routes} \mathrm{are} \mathrm{available} \mathrm{for} \mathrm{development} \mathrm{of} \mathrm{Carbon} \mathrm{nanotube}$ reinforced metal matrix composites (CNT-MMC). Powder metallurgy (PM) is cost-effective, robust and energy saving process. Hot deformation behavior of a $2.0 \mathrm{wt} \% \mathrm{CNT} / 2024 \mathrm{Al}$ nanocomposite was studied via high-temperature compression over a temperature and strain rate range of $200-400{ }^{\circ} \mathrm{C}$ and $0.001-0.1 \mathrm{~s}^{-1}$, respectively [3]. They found that microstructural examinations at a high strain rate, within the upper and lower temperature limits, revealed the occurrence of second-phase particle shearing, refinement, re-precipitation, and re-orientation. Mahmood et al. [4] have studied the time-dependent formulation of slightly weakened interface (SWI) model for an embedded carbon nanotube (CNT) in a polymer matrix with the aim to predict viscoelastic properties of CNT/polymer nanocomposites. In generally, the viscoelastic properties of CNT/polymer are lower than CNT-metal nanocomposites.

Ball milling is a technique to mix up the reinforcement and matrix materials before it goes through powder metallurgy process for nanocomposite development. In order to achieve targeted properties of nanocomposite, different combination of materials is formulated [5], [6], [7]. Thermal conductivity, mechanical and tribological property enhance significantly with different graphite shape. It is very important to successfully dispersed CNTs with the matrix material to attain desirable properties [6], [7]. Previous works done on the ball milling of CNT and aluminium

Umma Abdullahi' ${ }^{1}$ Md Abdul Maleque ${ }^{2} \otimes$ and Mohammad Yeakub Ali ${ }^{2}$

${ }^{1}$ Center for Energy Research and Training

Ahmadu Bello University, Zaria

Kaduna State, 810261 Nigeria

E-mail: ummaabdullahi@abu.edu.ng

2Department of Manufacturing and Materials Engineering,

International Islamic University Malaysia

PO Box 10, 50728 Kuala Lumpur, Malaysia

E-mail: maleque@iium.edu.my

Reference: Umma, A., Maleque, M. A. and Ali, M. Y. (2018). Characterization of Carbon Nanotube Reinforced Aluminium Nanocomposite Using Field Emission Scanning Electron Microscope. International Journal of Engineering Materials and Manufacture, 3(1), 63-67. 
mixtures with different speed and time for dispersion and homogenization of the CNT and aluminium. The effect of process variable such as milling time, control agent and CNT wt \% on the morphology of alloy powder was investigated by Esawi and Borady [8]. Another study was done by others on the CNT particle size and milling time and they concluded that the particle size and morphology changed significantly due to the parameter [9]. They also found that the addition of methanol as process control agent affect the mechanically alloyed powder mixture characteristic.

However, no information is available in literature on the characterisation of CNT dispersion with wide range of CNT into $\mathrm{Al}$ matrix in terms of mapping and line analysis. Therefore, this research studied and characterised carbon nanotube dispersion in ball milled CNT-Al nano-composite which was performed in a planetary ball mill equipment using FESEM.

\section{FEATURES OF FESEM}

A field emission scanning electron microscope (FESEM) is microscope that works with electrons (particles with a negative charge) instead of light. These electrons are liberated by a field emission source having the smallest probe diameters $(\sim 1.2 \mathrm{~nm})$ and with higher resolution. A FESEM is used to visualize very small topographic details on the surface or entire or fractioned objects. Researchers in materials, biology, chemistry and physics apply this technique to observe structures that may be as small as 1 nanometer. The main advantage of the FESEM is that high resolution imaging can be performed with very low accelerating voltages [10].

By using FESEM, topography, morphology, composition, mapping, crystallographic information, higher lateral resolution, onset field strength and investigation of the long-term stability can be measured.

The FESEM can be classified as a high vacuum instrument (less than $1 \times 10^{-7} \mathrm{~Pa}$ or $10^{-10} \mathrm{mbar}$ ). The vacuum allows electron movement along the column without scattering and helps to prevent discharges inside the instrument. Under vacuum, electrons generated by a field emission source (electron gun) are accelerated in a field gradient. The electron beam passes through electromagnetic lenses, focusing onto the specimen. As a result of the electrons bombardment, different types of electrons or signals (such as secondary electrons (SE), Backscattered electrons (BSE), AE, X-rays, light) are emitted from the specimen. The image is formed based on the detection and intensity of the secondary electrons. The applications of FESEM are semiconductor device cross section analyses for gate widths, gate oxides, film thicknesses, and construction details; advanced coating thickness and structure uniformity determination and small contamination feature geometry and elemental composition measurement [11].

\section{MATERIALS AND METHOD}

The matrix material in this investigation was Al powder (99.7\% purity) and the particle size was $78 \mu \mathrm{m}$ with the spherical shape. The reinforced material was multi-walled carbon nanotubes (MWCNTs) with a nominal diameter of $10 \mathrm{~nm}$, length of $5-15 \mu \mathrm{m}$ and surface area of $40-300 \mathrm{~m} 2 \mathrm{~g}-1$. The morphology of Al powder and MWCNT was investigated using FESEM and shown in Figure 1. There are four formulations with, 1, 1.5, 2 and $2.5 \mathrm{wt} \%$ CNT for development of CNT-AI nanocomposite. Initially, CNT-Al powders were mixed by hand shaking inside the tube using $10 \mathrm{~mm}$ diameter stainless steel ball for 10-15 mins. Then, this hand shacked mixture was placed in a stainless steel jars with the same ball. The ball milling was performed using high energy planetary ball mill equipment at a constant speed of $250 \mathrm{rpm}$ for 2 hours in presence of argon gas. The sample was compacted at a pressure of 2500 psi and sintered using hot isostatic press (HIP) machine (HP630) at 500oC and the argon gas was supplied at the pressure of 2500 psi for 60mins to control the atmosphere in the process. The CNTs dispersion was analysed using FESEM.

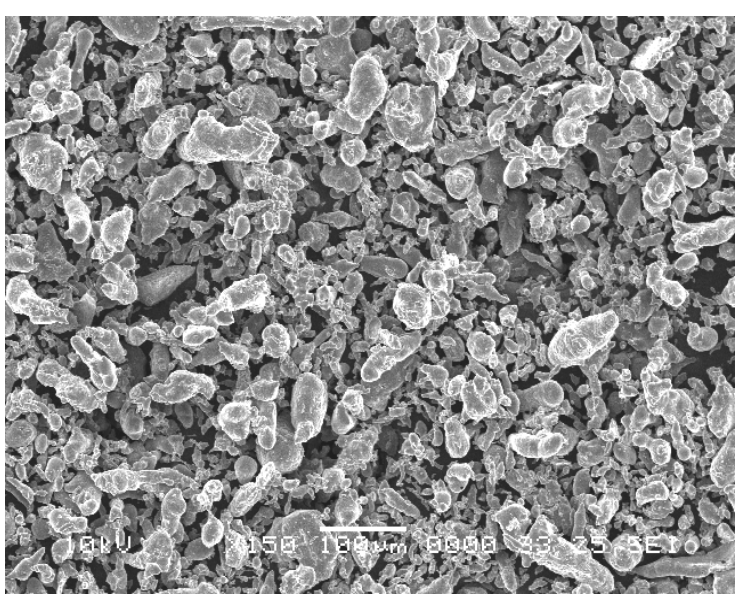

(a)

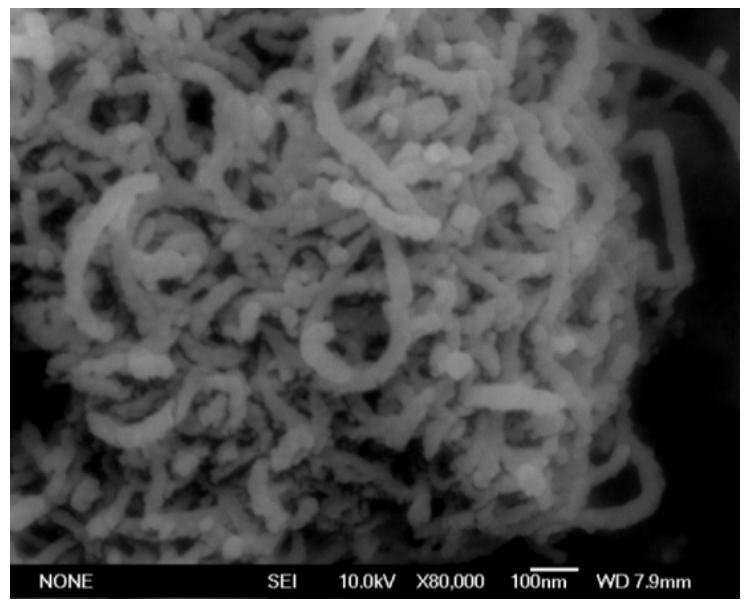

(b)

Figure1: Photo-micrograph of (a) aluminium powder and (b) CNT [3]. 


\section{RESULTS AND DISCUSSIONS}

From the FESEM image at higher magnification, the CNT was observed to be a long and thin tube like structure and appeared as individual molecules as expected. Figure 2 to 5 shows that the particles are plastically deformed due to effect of ball milling parameters resulting a typical flake structures of the nanocomposite.

With the increasing the milling time, the flake structure nanocomposite start changing to the sandwich structure up to the first few minutes of the milling time followed by welding of the particles together, and finally turns to the rough surface with course particle size. This is happen due to collision during grinding of the particles. The progressive welding of the particles continued due to effect of the milling time.

Fig. 3 shows the microstructure of $1.5 \mathrm{wt} \%$ CNT at $250 \mathrm{rpm}$ for different ball milling time. From the figure, it can be seen that both reinforcement and matrix particles are flattened because of the collision during ball milling. Spherical shape of CNT and Al mixtures was observed with increasing milling time. Similar observation was made from Fig. 2 and 4 for 1 and 2 wt\% CNT respectively; while for 2.5 wt\% some cluster was observed on the morphology (Fig. 5). However, similar result was observed by others but with different and higher milling time [6]. In terms of homogenization $1.5 \mathrm{wt} \%$ CNT was assume to have better and uniform CNT dispersion and it was attained in a short time at $250 \mathrm{rpm}$ milling speed. Higher CNT percentage into Al matrix demanded more milling time to homogeneously dispersed the mixture compared to when using a lower CNT percentage mixture. Uniform and homogeneously dispersed CNT has a significant effect in a light weight CNT-Al nanocomposite.

Hence, the dispersion and homogenous distribution of CNT in Al can significantly affected by the ball milling time and preliminary mixing of the powders. It can be said that the appropriate amount of bonding agent like process control agent and hand mixing of CNT and Al powder before ball milling are the main contributing factors toward the uniform dispersion and distribution of CNT powder in Al matrix.

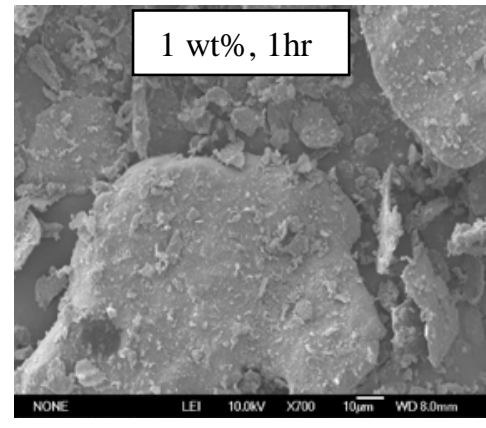

(a)

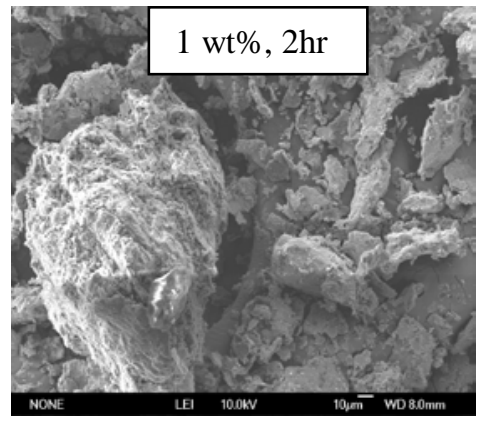

(b)

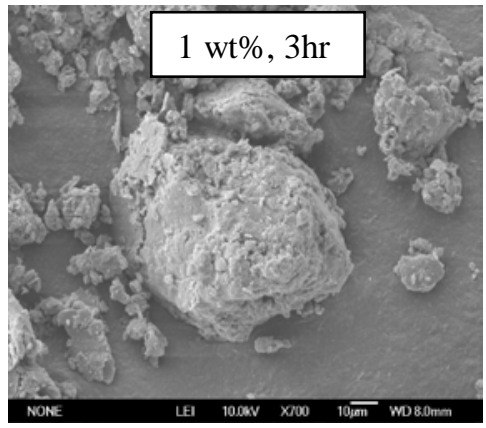

(c)

Figure 2: Microstructure of $1 \mathrm{wt} \%$ of CNT at $250 \mathrm{rpm}$ for different ball milling time.

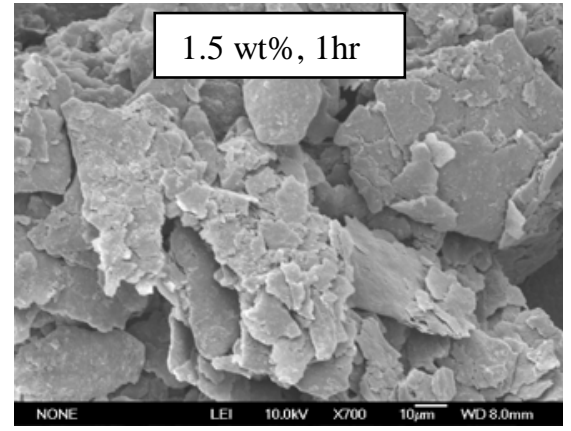

(a)

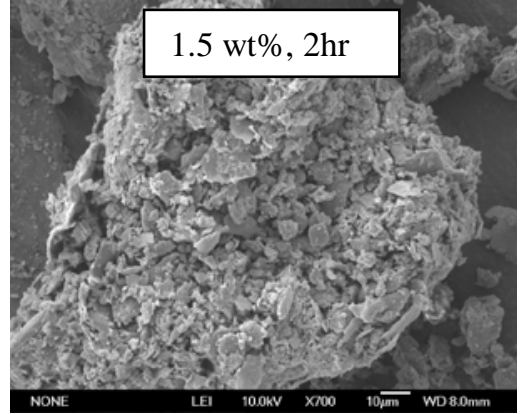

(b)

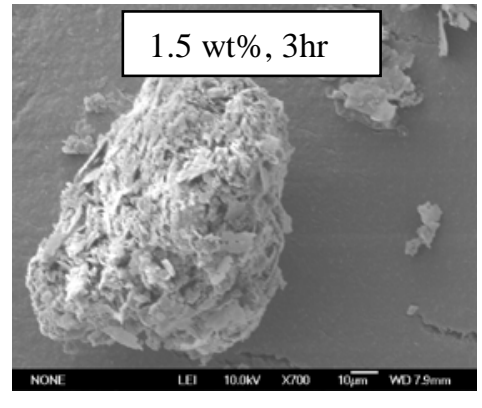

(c)

Figure 3: Microstructure of $1.5 \mathrm{wt} \%$ of CNT at $250 \mathrm{rpm}$ for different ball milling time. 


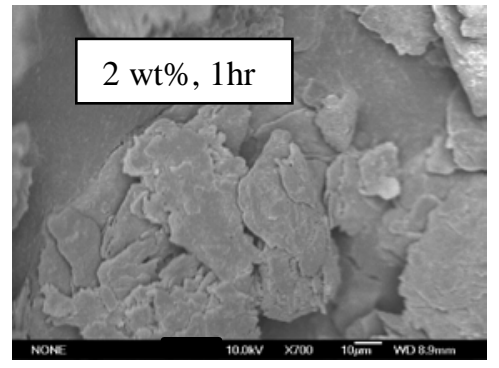

(a)

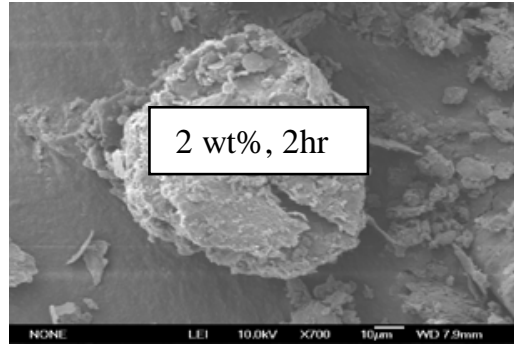

(b)

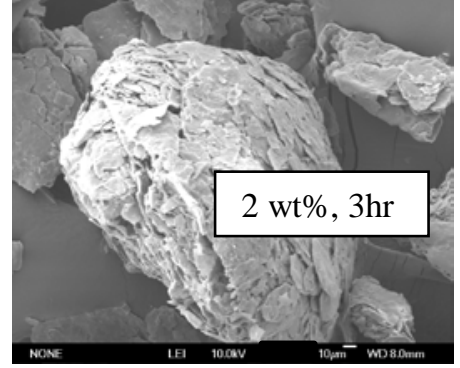

(c)

Figure 4: Microstructure and morphology of $2 \mathrm{wt} \%$ CNT at $250 \mathrm{rpm}$ for different ball milling time

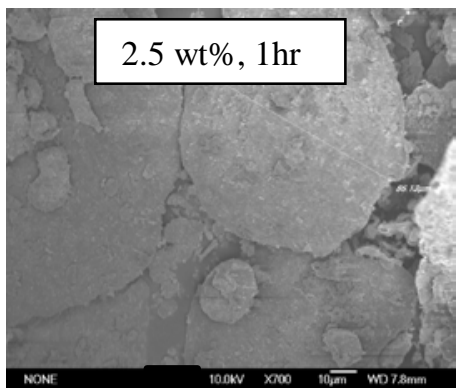

(a)

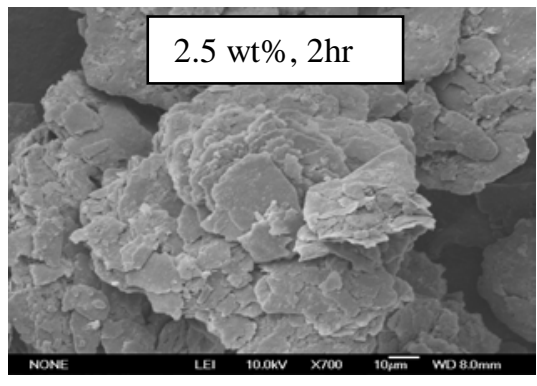

(b)

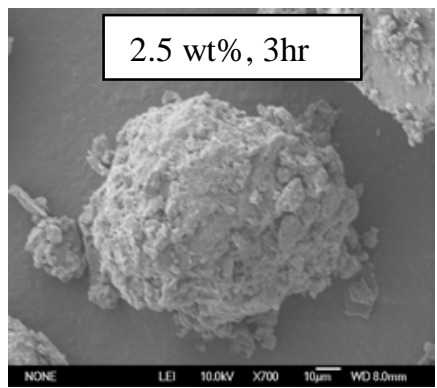

(c)

Figure 3: Microstructure of $2.5 \mathrm{wt} \%$ of CNT at $250 \mathrm{rpm}$ for different ball milling time.

\section{CONCLUSION}

The morphological characterization of the developed nanocomposite using different CNT weight percentage are presented and compared while the choice of the best CNT percentage in the development of CNT-Al nanocomposite was made based on the analysis of FESEM and the results showed homogeneous dispersion and distribution of CNTs in aluminium matrix. Ball milling time during the mixing of the powder and controlled atmosphere with argon in the furnace play important role on the sintered product of the CNT-Al nano-composite.

\section{ACKNOWLEDGEMENTS}

The authors would like to express their thanks to the Department of Manufacturing and Materials Engineering, IIUM for the support to carry out this research work.

\section{REFERENCES}

[1] lijima, S. (1991). Helical microtubules of graphitic carbon. Nature, 354(6348), 56-58.

[2] Bakshi, S. R., \& Agarwal, A. (2011). An analysis of the factors affecting strengthening in carbon nanotube reinforced aluminum composites. Carbon, 49(2), 533-544.

[3] F. Mokdad, D.L. Chen, Z.Y. Liu, D.R. Ni, B.L. Xiao, Z.Y. Ma, Hot deformation and activation energy of a CNTreinforced aluminum matrix nanocomposite, Materials Science and Engineering: A, Volume 695, 2017, $322-331$.

[4] Mahmood M. Shokrieh, Rahmatollah Ghajar, Ali R. Shajari, The effect of time-dependent slightly weakened interface on the viscoelastic properties of CNT/polymer nanocomposites, Composite Structures, 146, 2016,122 131.

[5] Maleque, M. A., Abdullah,U., I I Yaacob and Ali, M Y. (2016). Characterization of ball-milled carbon nanotube dispersed aluminium mixed powders. IOP Conf. Series: Materials Science and Engineering, 123, 1-6.

[6] Camargo, P. H. C., Satyanarayana, K. G., \& Wypych, F. (2009). Nanocomposites: synthesis, structure, properties and new application opportunities. Materials Research, 12(1), 1-39.

[7] Esawi, A., Morsi, K., Sayed, A., Taher, M., \& Lanka, S. (2010). Effect of carbon nanotube (CNT) content on the mechanical properties of CNT-reinforced aluminium composites. Composites Science and Technology, 70(16), 2237-2241. 
[8] Esawi, A. M., \& El Borady, M. A. (2008). Carbon nanotube-reinforced aluminium strips. Composites Science and Technology, 68(2), 486-492.

[9] Maleque, M A., Umma, A. and N Omar P. (2013). Wear mechanisms map of CNT-Al nano-composite. Procedia Engineering, 12, 247-253.

[10] https://www.mee-inc.com/laboratory-expertise/field-emission-sem-fesem/

[11] http://photometrics.net/field-emission-scanning-electron-microscopy-fesem/

[12] Umma, A., Maleque, M A., and Mohammad Y. A., (2012). Carbon nano tube reinforced aluminium matrix nano-composite: A critical review. Australian Journal of Basic and Applied Sciences, 6 (12), 69-75. 